\title{
High Strain Rate Compression of Martensitic NiTi Shape Memory Alloys
}

\author{
Ying Qiu ${ }^{1,2} \cdot$ Marcus L. Young ${ }^{1} \cdot \mathrm{Xu} \mathrm{Nie}^{3}$
}

Published online: 22 September 2015

(c) ASM International 2015

\begin{abstract}
The compressive response of martensitic NiTi shape memory alloys (SMAs) under high strain rate $\left(1200 \mathrm{~s}^{-1}\right)$ was investigated on a modified Kolsky (Split Hopkinson) compression bar. The single-loading momentum trapping system ensures precise deformation control $(1.4,1.8,3.0,4.8$, and $9.6 \%$ strain) and single loading during dynamic compression. With increasing strain, the phase transformation peaks shift toward lower temperatures, while the intensities of these peaks decrease and eventually disappear completely at strains above $\sim 7 \%$, where the onset of plastic deformation of reoriented martensite occurs. All transformation peaks are recoverable after deformation simply by annealing at $873 \mathrm{~K}\left(600{ }^{\circ} \mathrm{C}\right)$ for $30 \mathrm{~min}$, except those peaks corresponding to strains above $\sim 7 \%$ (e.g., $9.6 \%$ ) which return upon annealing, but at a lower temperature. XRD results showed the variation of the strongest diffraction peak from (111) to (111) crystal plane before and after high strain rate compression.
\end{abstract}

Keywords Martensite $\cdot \mathrm{NiTi}<$ Materials $\cdot$ Mechanical behavior $\cdot$ Monoclinic crystals $\cdot$ Stress-strain

Marcus L. Young

marcus.young@unt.edu

Ying Qiu

yingqiu@my.unt.edu

1 Materials Science and Engineering, University of North Texas, Denton, TX, USA

2 Mechanical and Energy Engineering, University of North Texas, Denton, USA

3 Mechanical Engineering, Southern Methodist University, Dallas, USA

\section{Introduction}

Martensitic shape memory alloys (SMAs) exhibit a unique shape memory effect where the material can be mechanically deformed and subsequently fully recovered by a simple thermal or electrical heating and cooling, thus "remembering" its original shape. These SMAs are found in a variety of aerospace [1-3], medical [4, 5], and civil [6, 7] applications over the last several decades. Among the alloy systems which exhibit the shape memory effect, NiTi-based SMAs have attracted more attention due to their excellent mechanical properties, good biocompatibility, and high corrosion resistance as well as their potential for structural and energy-absorbing applications [8-10]. In these types of applications, the NiTi SMA component is exposed to high strain rate deformation, large strain deformation, or both. It has been shown that the mechanical behavior of NiTi SMAs is dependent on strain rate, temperature, processing conditions, and deformation history [10].

Liu et al. [11-18] investigated the mechanical behavior and deformation mechanisms of martensitic NiTi SMAs under quasi-static loading. They reported Lüders-like deformation behavior and an asymmetric compression and tension stress-strain behavior, which results from different deformation mechanisms (predominantly by detwinning under tension and by dislocation propagation under compression). Furthermore, they also examined the microstructural variation of martensitic NiTi SMAs under tension and identified four different stages of strain. In order to better understand NiTi SMAs under shock or dynamic loading conditions, early research efforts involving high strain rate experiments on a conventional split Hopkinson pressure bar by Ogawa [19] showed that the strain rate effects on mechanical behavior of NiTi SMAs 
were related to phase transformation at the strain rates of $2-7 \times 10^{2} \mathrm{~s}^{-1}$. Chen et. al. [20] studied the compressive responses of a NiTi SMA under austenite phase at the strain rates ranging from 0.001 to $750 \mathrm{~s}^{-1}$ and found that the compressive stress-strain behavior of NiTi SMA is related to strain rate. That conclusion is based on the results that (1) the stress-strain loops are open due to the residual deformation during dynamic loading, while these loops are closed under quasi-static loading conditions; (2) the transition stresses from a stiff behavior to a soft behavior are different under dynamic and quasi-static loading conditions. Similar conclusions were obtained by Nemat-Nasser et al. [21]. In another study, Chen et al. [7] investigated the mechanical behavior of the same materials at temperatures slightly above and below the austenite finish transformation temperature and reported that the slope of the stress-strain curve is stiffer at higher temperatures. Very high strain rate (greater than $10,000 \mathrm{~s}^{-1}$ ) response of a NiTi SMA was achieved on a mini-Hopkinson bar system with stepped striker bars by Nemat-Nasser et al. [22]. They also carried out experiments on the cyclic response of NiTi SMA at high strain rates and temperatures [23]. Miller et al. [24] and Jiang et al. [25] studied the damage evolution and fracture mechanism under high strain rate loading conditions and observed voids on the specimens after deformation. Millett et al. [26] examined the shock behavior of NiTi SMAs during one-dimensional shock loading at impact velocities of $200-875 \mathrm{~ms}^{-1}$. The influence of high strain rate on the functional properties (e.g., two-way shape memory effect) of NiTi SMAs was conducted by Bragov et al. [27]. With a digital image correlation technique, the strain field of NiTi SMAs was measured by Saletti et al. [28] under moderate strain rate. Patman et al. [29] studied the effect of strain rates and temperatures on the compressive response of $\mathrm{NiTi}$ SMAs and found that superelastic strain range increases with increasing strain rate and temperature when martensite and austenite coexisted in one sample, which is different from samples with either pure austenite phase or pure martensite phase. Adharapurapu et al. [30-32] determined the effects of strain rate, temperature, aging conditions, cold work, and texture on mechanical properties of NiTi SMAs. The compressive response of NiTi SMAs in the martensitic state was examined at a strain rate of $3000 \mathrm{~s}^{-1}$ by Liu et al. [33]. Although the experimental results on mechanical behavior of superelastic NiTi SMAs under both quasi-static and dynamic loading conditions, in terms of temperature, have been reported, the influence of high strain rate on phase transformation, crystal structure, and microstructure of martensitic NiTi SMAs has not been specifically investigated. Furthermore, previous high strain rate studies on NiTi SMAs were primarily focused on the dynamic constitutive response of the materials [19-34]. Some high strain rate research has correlated the macroscopic stress-strain behavior with the microstructural evolution of either Ni-rich NiTi SMAs or austenitic SMAs [22, 24, 25, 28, 31, 32]. For martensitic NiTi SMAs, currently no studies have focused on the correlation between the macroscopic stress-strain behavior and the microstructural evolution/thermal changes associated with phase transformation. Besides examining this correlation, the experimental procedure of previous high strain rate studies were not carried out in a manner where constant strain rate loading and single loading can be maintained. In this study, we particularly focus on developing a novel experimental procedure, which involves a Kolsky bar wave shaping technique and single-loading technique, to realize well-controlled constant strain rate and single loading of the specimens as well as to precisely recover the specimens after each incremental deformation. By following this procedure, the microstructural changes can be quantitatively related to the imposed specimen deformation under dynamic loading conditions and be compared with microstructural/thermal changes associated with phase transformation. Using this new procedure from our previous study [34], we reported different mechanical behaviors of martensitic NiTi SMA under quasi-static and dynamic loading conditions and its influence on the phase transformation characteristics. Here, we examine the relationship between phase transformations, crystal structure, and microstructure of martensitic NiTi SMAs compressed to different strains under high strain rate loading conditions. This is the first time that the mechanical results have been correlated with microstructural observations for martensitic NiTi SMAs under high strain rate loading conditions.

\section{Experimental}

Martensitic NiTi SMA rods with $6.35 \mathrm{~mm}$ in diameter, provided by ATI Specialty Alloys and Components (Albany, Oregon), were investigated in this study. The nominal composition of the rod is 49.5 at. $\% \mathrm{Ni}$ and 50.5 at.\% Ti. An oil-cooled diamond wire saw (MTI Corporation, STX202) was used to cut compression samples and then all samples were slightly etched in a dilute nitride acid solution to remove the oxidized surface layer.

High strain rate compressive tests were conducted on a modified Kolsky compression bar at room temperature. As illustrated in Fig. 1, the Kolsky compression bar consists of a striker, an incident bar, a transmission bar, and a momentum bar. A gas gun accelerates the striker to impact the incident bar and generates an elastic compressive wave which travels down to the other end of the incident bar. The sample, which sits between the incident bar and transmission bar, is deformed by the incoming loading pulse, which results in a reflected pulse that travels back into the incident bar, and a transmitted pulse that enters the 


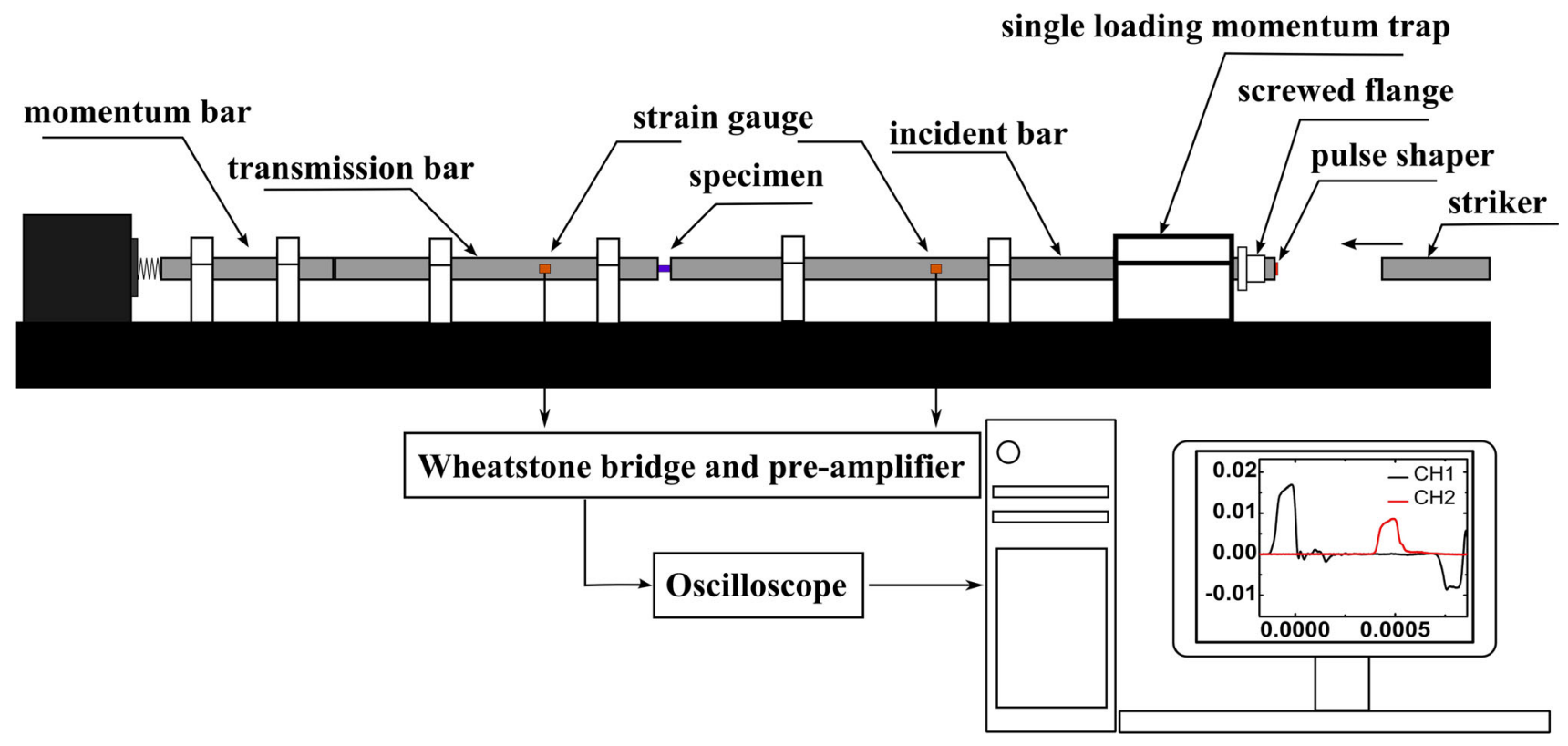

Fig. 1 Schematic diagram of modified Kolsky compression bar

transmission bar. The momentum bar diverts the excessive energy into a shock absorber system. The pulse shaper on the impact end of the incident bar ensures constant strain rate deformation and maintains dynamic stress equilibrium in the specimen. The single-loading momentum trapping system facilitates precise deformation control through engaging the screwed flange with the rigid single loading momentum trap. The strain gages attached on incident and transmission bars collect the incident, reflected, and transmitted pulses as a function of time. According to the one-dimensional stress wave theory, the stress and strain response of the sample can be calculated from the transmitted and reflected pulses, respectively. The strain rate, strain, and stress histories of the sample can be calculated by the formulas as follows:

$\dot{\varepsilon}_{\mathrm{s}}(t)=-\frac{2 C_{0}}{L_{\mathrm{s}}} \varepsilon_{R}(t)$

where $C_{0}$ is the 1-D elastic stress wave speed in the bars, $L_{\mathrm{s}}$ is the length of the sample, and $\varepsilon_{\mathrm{R}}(t)$ is the strain history of the reflected pulse;

$\varepsilon_{\mathrm{s}}(t)=-\frac{2 C_{0}}{L_{\mathrm{s}}} \int_{0}^{t} \varepsilon_{\mathrm{R}}(\tau) d \tau$

$\sigma(t)=\frac{A_{0} E}{A_{\mathrm{s}}} \varepsilon_{\mathrm{T}}(t)$

where $A_{0}$ is the cross-sectional area of the initial sample, $A_{s}$ is the cross-sectional area of the transmission bar, $\boldsymbol{E}$ is the Young's modulus of the bar, and $\varepsilon_{\mathrm{T}}(t)$ is the strain history of the transmission pulse.

Samples for high strain rate compression had an aspect ratio of $1: 1$, which was chosen to (a) decrease the buckling effect which occurs with large aspect ratio samples and (b) eliminate the barreling effect which occurs with small aspect ratio samples. A lubricant (Dow corning high vacuum grease) was applied on both ends of the specimen to reduce the friction at the contact surfaces between the Kolsky compression bars and the sample.

Scanning electron microscopy (SEM) with energy dispersive spectroscopy (EDS) was conducted on an FEI Nova 200 NanoLab instrument. In order to reveal the grain boundary and martensitic microstructure, martensitic NiTi rod compression samples were examined in cross section after polishing with 0.02 micron colloid silica and then after electropolishing using a LectroPol-5, Struers electropolishing machine using $20 \%$ (by volume) $\mathrm{H}_{2} \mathrm{SO}_{4}$ and $80 \%$ (by volume) $\mathrm{CH}_{3} \mathrm{OH}$ as an electrolyte.

Differential scanning calorimetry was carried out on samples with a mass between 10 and $50 \mathrm{mg}$ by using Netzsch DSC 204 F1 Phoenix differential scanning calorimeter (DSC). The DSC samples were sealed in coldweldable, lidded aluminum crucibles, and then heated and cooled between $223 \mathrm{~K}\left(-50{ }^{\circ} \mathrm{C}\right)$ and $373 \mathrm{~K}\left(100{ }^{\circ} \mathrm{C}\right)$ at a scanning rate of $10 \mathrm{~K} / \mathrm{min}$ in a helium atmosphere. Only the first cooling and second heating data were used for analysis after the samples were heated from room temperature [about $298 \mathrm{~K}\left(25^{\circ} \mathrm{C}\right)$ ] to $373 \mathrm{~K}\left(100{ }^{\circ} \mathrm{C}\right)$, held for $3 \mathrm{~min}$ to reach thermal equilibrium, and cooled down to $223 \mathrm{~K}\left(-50{ }^{\circ} \mathrm{C}\right)$, held for another $3 \mathrm{~min}$, and heated up 
again to $373 \mathrm{~K}\left(100{ }^{\circ} \mathrm{C}\right)$. X-ray diffraction (XRD) measurements were conducted on Rigaku Ultima III X-ray diffractometer (XRD), which was operated at $40 \mathrm{kV}$ and $44 \mathrm{~mA}$ with a $\mathrm{CuK} \alpha$ radiation source. Diffraction patterns were collected from $20^{\circ}$ to $90^{\circ}$ at a scanning rate of $1 \% \mathrm{~min}$.

\section{Results and Discussion}

As illustrated in Fig. 2, the cross section of the as-received martensitic NiTi rod shows a martensitic NiTi matrix with $\mathrm{Ti}_{2} \mathrm{Ni}$ particles (white arrow in Fig. 2a), which are typically located at the grain boundaries. $\mathrm{Ti}_{2} \mathrm{Ni}$ particles are known to bear a higher mechanical load upon straining, which induces crack propagation and brittle fracture during mechanical testing [35]. The grains shown in Fig. 2a range between 5 and $20 \mu \mathrm{m}$ in size. Well-aligned martensitic bands on the order of about $1 \mu \mathrm{m}$ in width and running the length of the grain are observed within these grains, Fig. 2b.

Due to the different deformation mechanisms of martensite twins under quasi-static loading, martensitic NiTi SMAs exhibit 4-stage stress-strain curves [13]. These deformation stages occur in the following order and consist of elastic deformation of martensite, reorientation of martensite, elastic deformation of reoriented martensite, and plastic deformation of reoriented martensite. As illustrated in Fig. 3, these 4 stages are also observed under high strain rate loading. Figure 3 shows a series of stress-strain curves from martensitic NiTi SMA rods which were separately compressed to $1.4,1.8,3.0,4.8$, or $9.6 \%$ strain under high strain rate $\left(1200 \mathrm{~s}^{-1}\right)$.

Similar results can be found in Liu et al. [33]. The variation of the stiffness on loading and unloading under high strain rate compression (Table 1) can be observed.

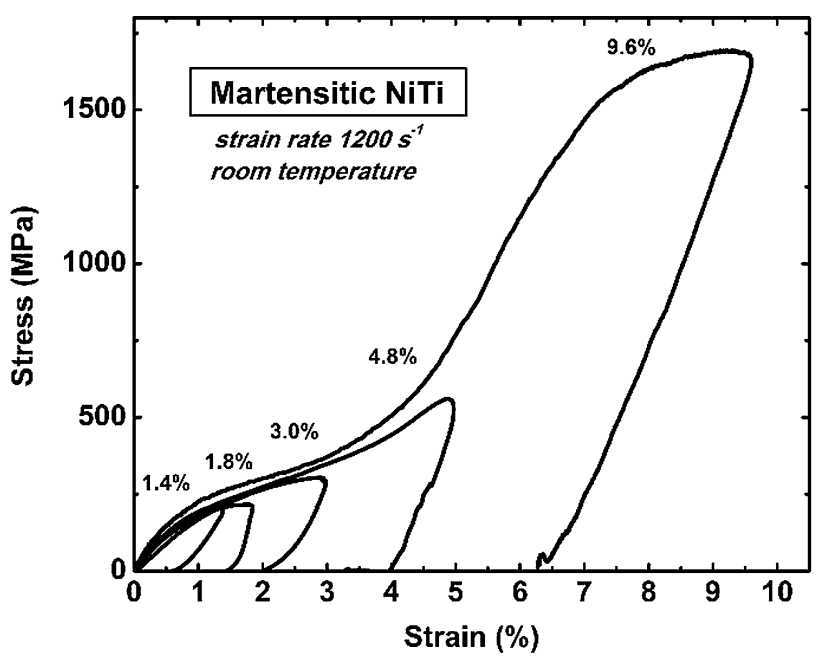

Fig. 3 Series of compressive stress-strain curves of martensitic NiTi SMA rods under high strain rate $\left(1200 \mathrm{~s}^{-1}\right)$

Table 1 Maximum applied strain, stiffness on loading, and unloading for martensitic NiTi SMAs after high strain rate compression

\begin{tabular}{llllll}
\hline$\varepsilon_{\text {max }}(\mathrm{Pct})$ & 1.4 & 1.8 & 3.0 & 4.8 & 9.6 \\
$E_{\text {load }}(\mathrm{GPa})$ & 25 & 25 & 20 & 23 & 33 \\
$E_{\text {unload }}(\mathrm{GPa})$ & 48 & 47 & 34 & 52 & 28 \\
\hline
\end{tabular}

This variation is commonly observed as the "elastic" region is rarely purely linear for martensite due to the fact that the curve contains both elastic behavior as well as an increasing amount of martensite reorientation (detwinning), which softens the curve and the apparent modulus, and also some plastic deformation [36, 37]. Besides this difficulty, some other unavoidable factors can also induce variation in apparent modulus: (1) the strain rate is increasing at the early stage of loading (true only for
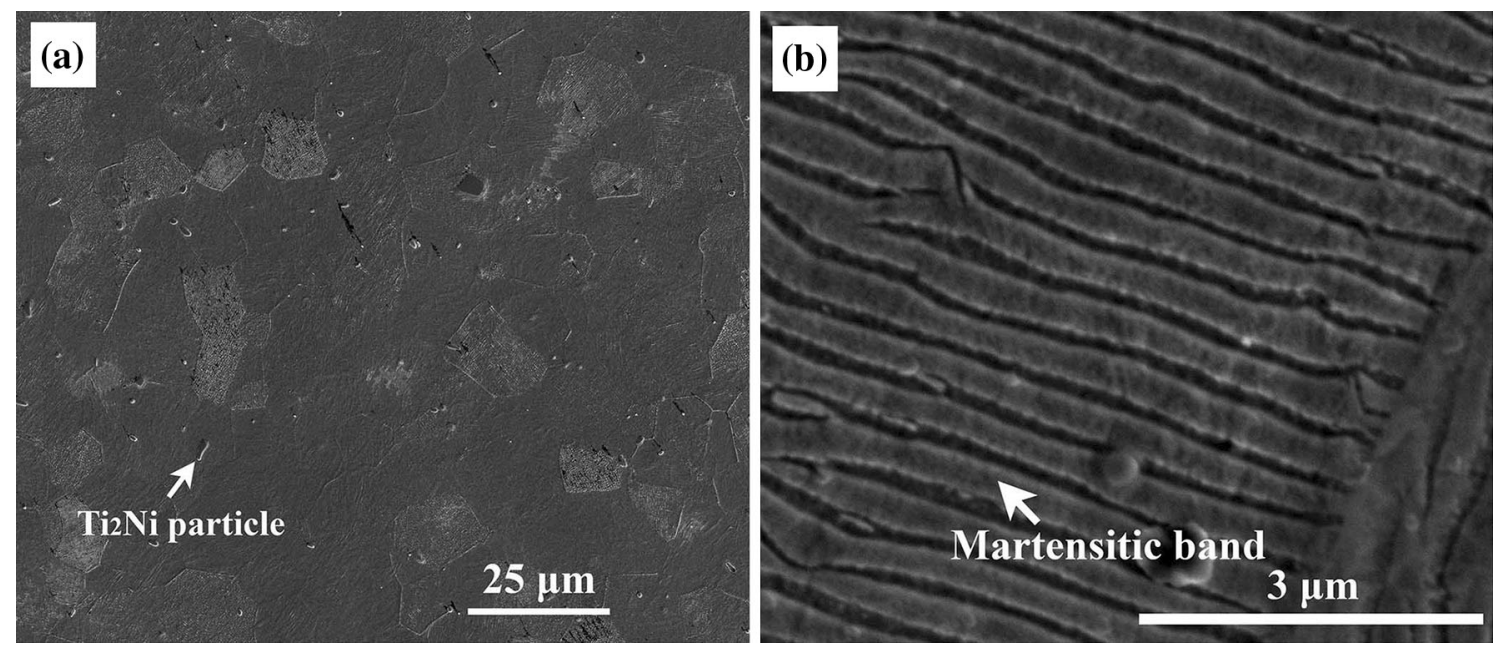

Fig. 2 SEM images of the as-received martensitic NiTi rod after electropolishing a multiple grains and $\mathbf{b}$ single grain 
dynamic testing), (2) several uncertainties such as system and sample misalignment (true for both quasi-static and dynamic testing), wave dispersion during wave propagation (true only for dynamic testing), indentation of the bars and early stress equilibrium (true only for dynamic testing), and (3) the stress-strain data under high strain rate loading conditions is calculated from the electrical signal, which is directly collected by an oscilloscope, so the selection of the starting point for data reduction has an influence on the results, which is difficult to quantify (true only for dynamic testing). It is well known that the observed modulus in a macroscopic stress-strain curve for NiTi is not reflective of a true modulus for martensite (near $70 \mathrm{GPa}$ from neutron diffraction and synchrotron XRD [36-41]). Literature reports the apparent elastic modulus of martensite to range between 20 and $70 \mathrm{GPa}$ [36-41]. Thus, the apparent elastic modulus observed here is within the range of those reported in the literature and are essentially the same during loading up to $4.8 \%$ strain.

Each curve was obtained from a NiTi compression rod sample which was initially in the as-received state. The first stress-strain curve (1.4\% maximum strain) shows an elastic modulus of about $25 \mathrm{GPa}$, which is within the range of elastic moduli values reported in the literature [37, 38, 41]. The residual strain indicates that martensite reorientation occurs before the sample was compressed to $1.4 \%$, which is consistent with the results in Liu et al. [12]. Liu et al. [12] observed that the onset of the stress-plateau ( $\sim 1.2 \%$ strain) on the stress-strain curve indicates the initiation of the martensite reorientation process. Similar mechanical behavior was also observed in the subsequent two stress-strain curves (1.8 and $3.0 \%$ maximum strain) except that higher stress levels were obtained at larger strains, with $204.3 \mathrm{MPa}$ at $1.4 \%$ strain $\left(E_{\text {load }}=25 \mathrm{GPa}\right)$, $215.7 \mathrm{MPa}$ at $1.8 \%$ strain $\left(E_{\text {load }}=25 \mathrm{GPa}\right)$, and $299.3 \mathrm{MPa}$ at $3.0 \%$ strain $\left(E_{\text {load }}=20 \mathrm{GPa}\right)$. As the strain increases, there is also an increase in deviation from linearity, which indicates that in addition to elastic deformation of martensite, there is also martensite reorientation. The stress-strain curve up to $4.8 \%$ also shows both elastic deformations of martensite and martensite reorientation as well as a clear inflection point at about $450 \mathrm{MPa}$ which indicates that elastic deformation of reoriented martensite has also started. The slope of the stress-strain curve increases from 7.8 to $14.6 \mathrm{GPa}$ at this inflection point. Finally, the stress-strain curve up to $9.6 \%$ exhibits all four stages (elastic deformation of martensite, reorientation of martensite, elastic deformation of reoriented martensite, and plastic deformation of reoriented martensite), which are distinctly observable in Fig. 3. The last inflection point (correlating to plastic deformation of reoriented martensite) occurs at about $1600 \mathrm{MPa}$ (the corresponding strain is about $7 \%$ ) in the sample plastically deformed to $9.6 \%$. This behavior likely indicates that defects such as dislocations and residual strain after unloading accumulate with increasing strain as is consistent with previous research [18].

DSC measurements were conducted on the martensitic NiTi samples before and after high strain rate $\left(1200 \mathrm{~s}^{-1}\right)$ compression to the strain of $1.4,1.8,3.0,4.8$, or $9.6 \%$. As indicated in Fig. 4, the phase transformation temperatures of the as-received sample are $M_{\mathrm{s}}=324.4 \mathrm{~K}\left(51.4{ }^{\circ} \mathrm{C}\right)$, $M_{\mathrm{f}}=311.8 \mathrm{~K}\left(38.8^{\circ} \mathrm{C}\right), A_{\mathrm{s}}=347.5 \mathrm{~K}\left(74.5^{\circ} \mathrm{C}\right)$, and $A_{\mathrm{f}}=355.4 \mathrm{~K}\left(82.4^{\circ} \mathrm{C}\right)$, respectively. A 2-step transformation, corresponding to a transformation from $\mathrm{B} 19^{\prime}$ to $\mathrm{R}$-phase and then R-phase to B2, is observed during heating [42]. With increasing compression strain up to $4.8 \%$ strain, the peak corresponding to the R-phase to B2 (red curves in Fig. 5) transformation increases, while the peak corresponding to B19' to R-phase (blue curves in Fig. 5) transformation decreases. Both transformation peaks increase in intensity and remain at a fixed temperature regardless of the amount of strain, with the exception of strain up to $9.6 \%$. This is due to the fact that the martensite stabilization effect $[16,43,44]$ commonly observed is removed after the first heating cycle during DSC, where we only show the first cooling curve and the second heating curve whereby all stabilization by deformed martensite has been removed at strains below $9.6 \%$ strain. At the same time, the 1-step peak observed during cooling which corresponds to the $\mathrm{B} 2$ to $\mathrm{B} 19^{\prime}$ transformation gradually decreases in intensity and temperature. The increasing intensity in both cases indicates that, as the strain is increased, more energy is stored in the sample after deformation, which is also confirmed when examining the

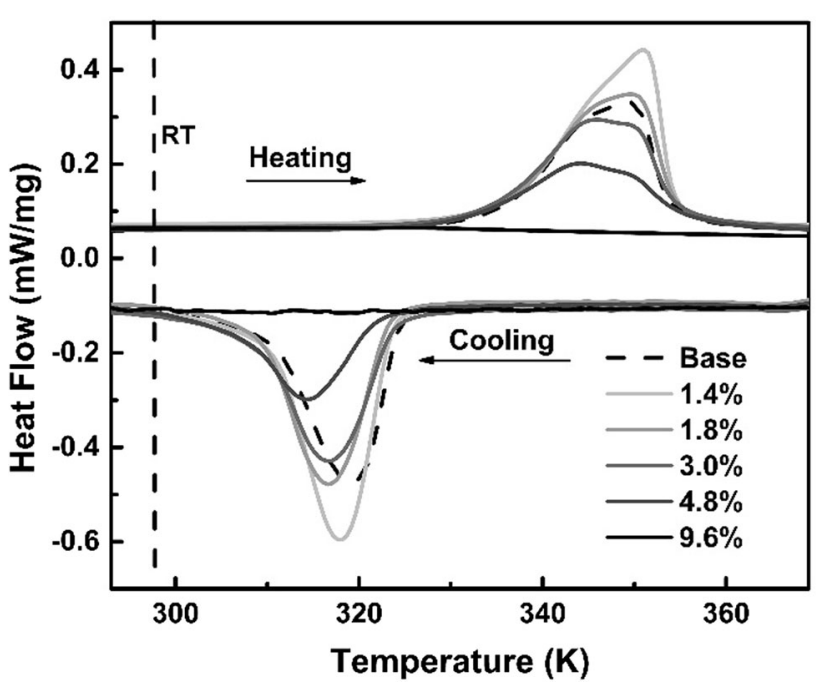

Fig. 4 DSC curves of the martensitic NiTi SMA samples before and after high strain rate $\left(1200 \mathrm{~s}^{-1}\right)$ compression to the strain of $1.4,1.8$, $3.0,4.8$, or $9.6 \%$ 


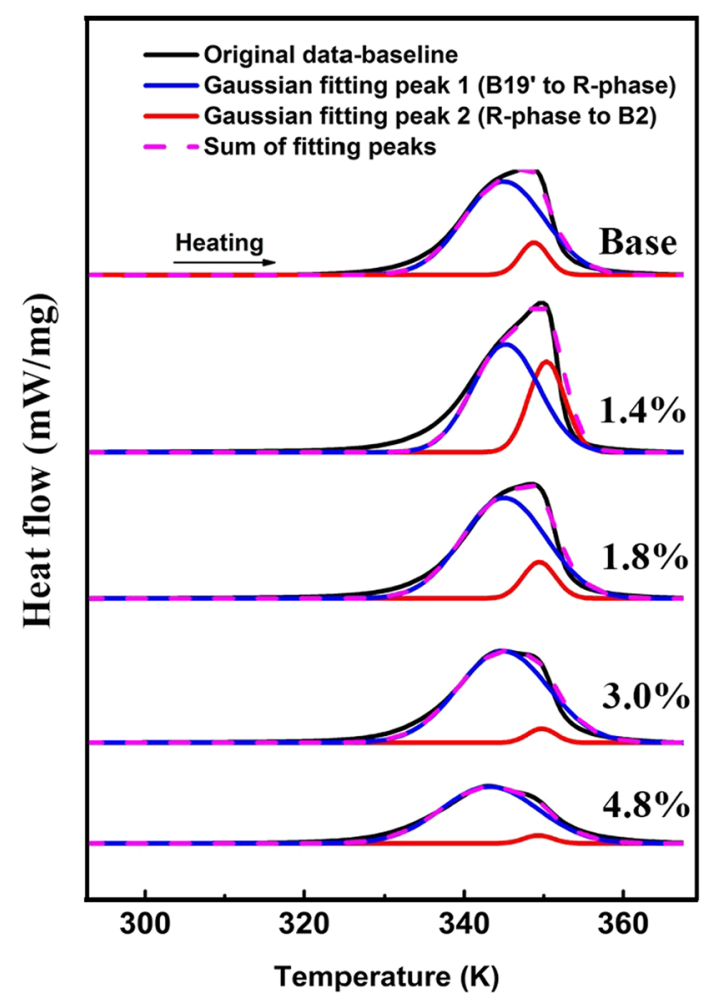

Fig. 5 DSC heating curves of martensitic NiTi SMA before and after high strain rate $\left(1200 \mathrm{~s}^{-1}\right)$ compression to the strain of 1.4, 1.8, 3.0, or $4.8 \%$ (peak fitting by Gaussian)

increase in area under the curve in Fig. 3 with increasing deformation before the fourth stage (plastic deformation of reoriented martensite). Apparently, there is a threshold strain between 4.8 and $9.6 \%$, below which the phase transformation feature (i.e., the shape memory feature) is present and above which phase transformation is completely removed. That threshold value is likely at $\sim 7 \%$ strain according to Fig. 3, which is much lower than that under quasi-static loading conditions [45], and is likely due to more plastic deformation of reoriented martensite occurring during high strain rate loading compression as compared to quasi-static loading compression. Figure 5 shows the decoupling of the two-step transformation which occurs during heating. A Gaussian peak fitting was performed. The B19' to R-phase peak broadens and lowers down gradually with increasing strain, while the other peak is sensitive to increasing strain. It increases at the strain of $1.4 \%$ and then decreases with higher strains. This is due to the strain energy induced by the distorted crystal planes as shown in Fig. 6.

In order to examine this change in crystal structure after high strain rate compression, XRD patterns were obtained from each sample as shown in Fig. 6. The diffraction peaks correspond very well with diffraction peaks from monoclinic martensitic NiTi (PDF\#: 00-035-1281). According to the peak position and its relative intensity, the (101), (020),

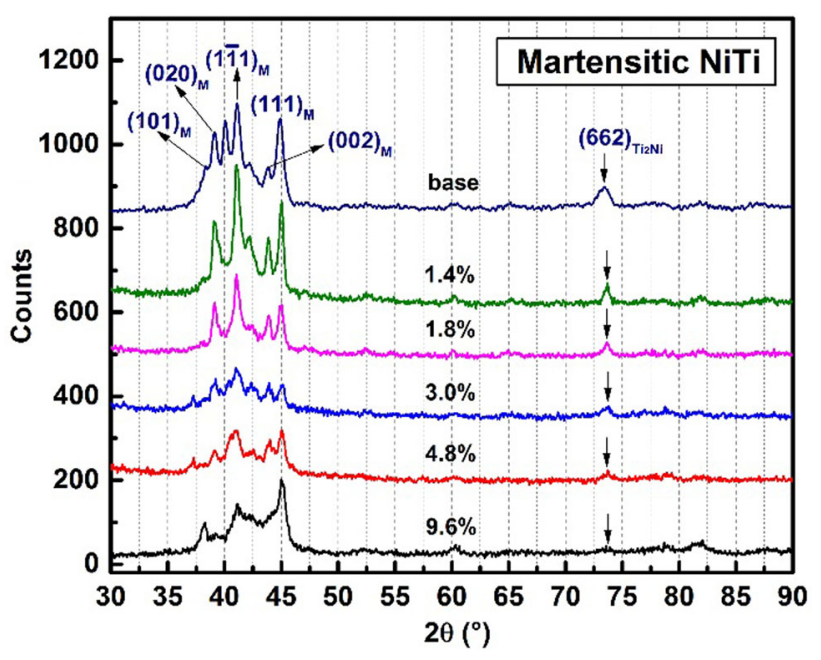

Fig. 6 XRD patterns of the sample before and after compression to the strain of $1.4,1.8,3.0,4.8$, or $9.6 \%$

(1111), (002), and (111) planes of martensitic NiTi are identified as well as the (662) plane from $\mathrm{Ti}_{2} \mathrm{Ni}$ phase, which continuously decreases with increasing compressive strain. There is no apparent peak shift after compression; however, the peak intensity decreases with increasing strain except at the strain of $1.4 \%$, at which the deformation stage is close to the onset of martensite reorientation (as shown in Fig. 3). At all strain rate loading conditions, the diffraction peaks indicate that martensite is present at room temperature; however, the orientation changes significantly and, based on DSC results in Fig. 4, the phase transformation is removed when the orientation is as shown for the diffraction peaks for $9.6 \%$ strain. The most intense diffraction peak for compression up to 1.4, $1.8,3.0$, or $4.8 \%$ is the (111) plane, while the most intense diffraction peak for compression up to $9.6 \%$ strain is the (111) plane, which indicates a reorientation of martensite. Hence, large strain compression under high strain rate results in large residual strain (as indicated in Fig. 3), which is accommodated by the severe distortion of the crystal planes.

SEM images of martensitic NiTi SMAs before and after high strain rate compression are shown in Fig. 7a-f. Before compression, grain boundaries are relatively easy to identify and the martensite bands align in the same direction within each individual grain and appear ordered. As strain is increased, the ordered regions of martensite as shown in Fig. 7b-e exhibit finer bands which can still be reversibly transformable, then martensite bands and grains begin to break apart and become disordered. When the compressive strain reaches $9.6 \%$ strain, grain boundaries and ordered martensite become difficult to distinguish.

Figure 8 shows DSC curves from the deformed samples after annealing at $873 \mathrm{~K}\left(600{ }^{\circ} \mathrm{C}\right)$ for $30 \mathrm{~min}$. For samples 

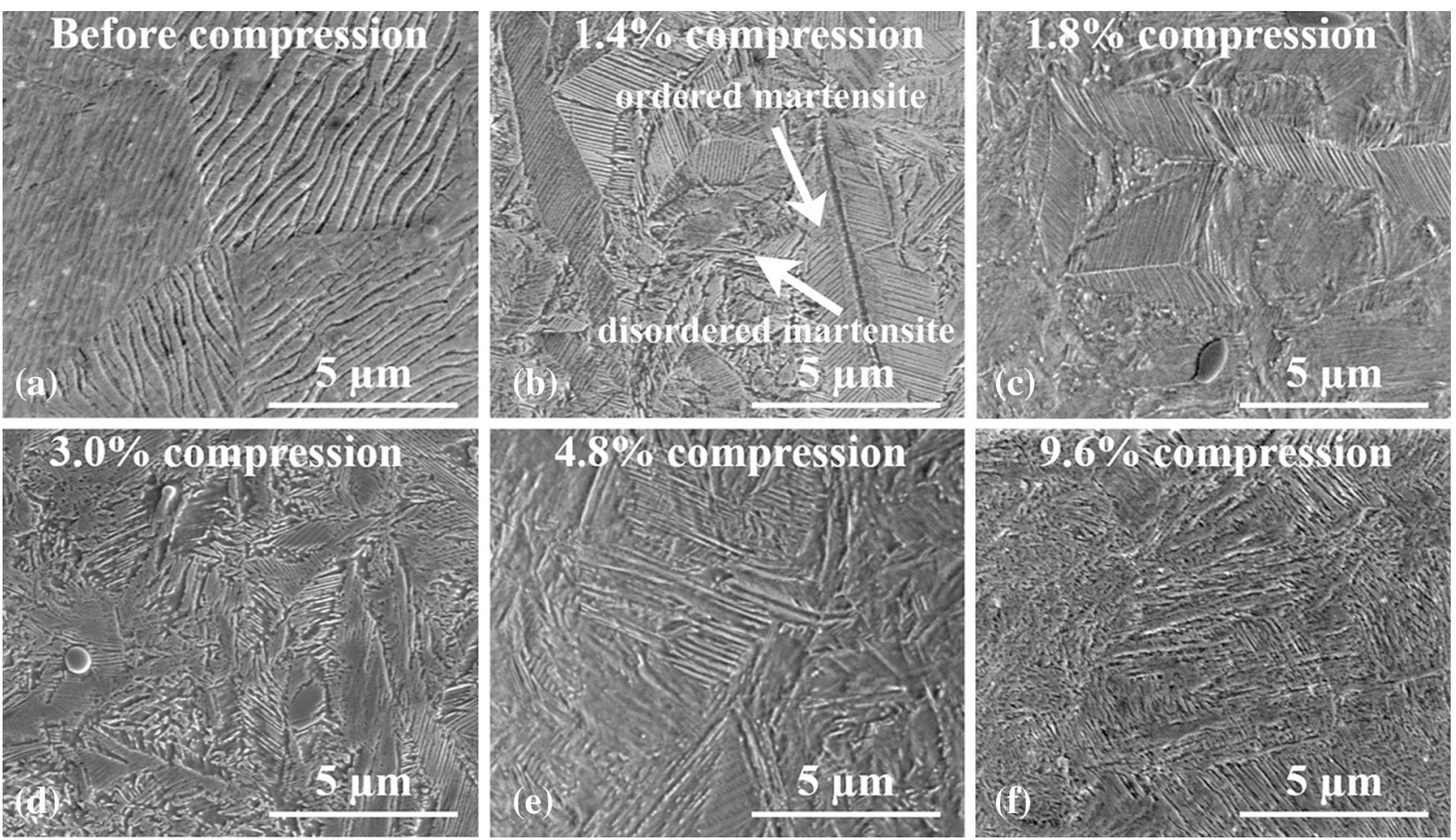

Fig. 7 SEM images of martensitic NiTi shape memory alloys before and after high strain rate compression a before compression, b $1.4 \%$ compression, c $1.8 \%$ compression, $\mathbf{d} 3.0 \%$ compression, e $4.8 \%$ compression, and $\mathbf{f} 9.6 \%$ compression

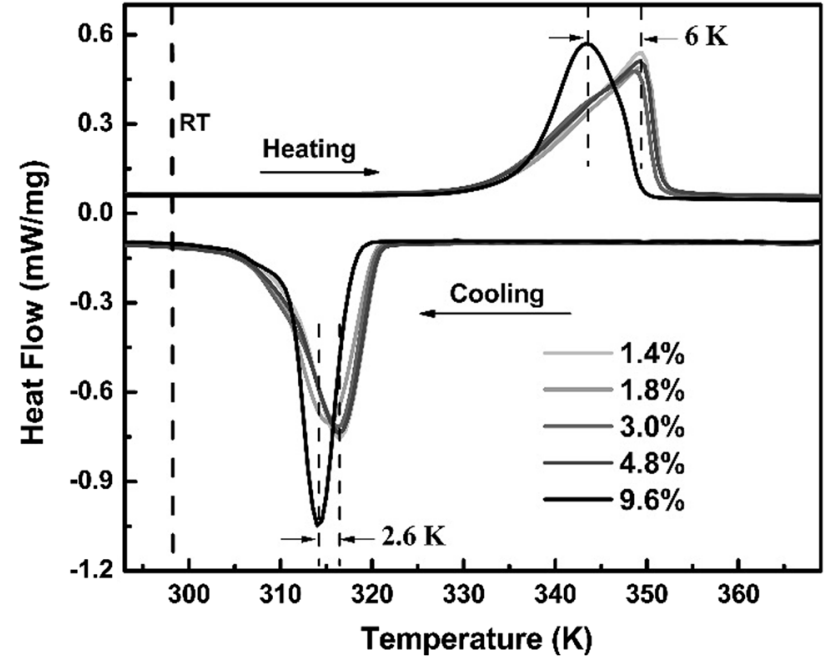

Fig. 8 DSC curves of deformed samples annealed at $873 \mathrm{~K}\left(600{ }^{\circ} \mathrm{C}\right)$ for $30 \mathrm{~min}$

compressed to the strain of $1.4,1.8,3.0$, or $4.8 \%$, the phase transformation peaks are all fully recovered with almost the same peak positions and intensities. Macroscopically, the sample dimensions are also fully recovered after annealing for these compression strains, which correspond to the deformation stages before plastic deformation of reoriented martensite occurs. In the case of $9.6 \%$ strain where plastic deformation of reoriented martensite occurred as indicated in Figs. 3 and 7f, the phase transformation peaks completely disappeared after deformation and return after annealing, but are shifted down in temperature (i.e., $2.6 \mathrm{~K}\left(2.6^{\circ} \mathrm{C}\right)$ lower for the martensite phase transformation and $6 \mathrm{~K}\left(6^{\circ} \mathrm{C}\right)$ lower for the reverse phase transformation). When the compressive strain is smaller than $\sim 7 \%$, elastic deformation of martensite, reorientation of martensite, and elastic deformation of reoriented martensite occur, whereas in addition to these three stages of deformation, irrecoverable plastic deformation of reoriented martensite occurs at strains above $\sim 7 \%$ according to Fig. 3. This plastic deformation induces progressive disordering of martensite which can be seen in the SEM images in Fig. 7f where grain boundaries and ordered martensite have become completely fragmented. Consequently, phase transformation peaks or transformability disappear as shown in Fig. 4. During annealing, nucleation and growth of new austenite occurs, which transforms into ordered martensite upon cooling [45]. Defects such as dislocation network induced by compressive deformation can be removed more completely or the defect configuration can be rearranged in the formation of new austenite. This new austenite results in a permanent strain in the material after phase transformation to room temperature. Therefore, the transformation temperatures drop slightly after the $9.6 \%$ deformed sample was annealed. 


\section{Conclusions}

In this research, martensitic $\mathrm{NiTi}$ rods were compressed separately at a strain rate of $1200 \mathrm{~s}^{-1}$ to a strain of $1.4,1.8$, $3.0,4.8$, or $9.6 \%$. DSC measurements and XRD analysis were carried out to investigate the influence of high strain rate at five different strain levels on the phase transformation and crystal structures of martensitic NiTi SMAs. Several conclusions are drawn upon the results:

1. A 4-stage stress-strain curve for a martensitic NiTi SMA was obtained at the strain rate of $1200 \mathrm{~s}^{-1}$. These stages correspond to elastic deformation of martensite, reorientation of martensite, elastic deformation of reoriented martensite, and plastic deformation of reoriented martensite.

2. A critical compressive strain is observed between 4.8 and $9.6 \%$ under high strain rate loading (e.g., strain rate of $\left.1200 \mathrm{~s}^{-1}\right)$. When the deformation strain is above that value, the phase transformation, which is related to the shape memory effect, does not occur. This response is a direct result of an accumulation of large residual strains likely due to the occurrence of plastic deformation of reoriented martensite, which initiates at $\sim 7 \%$ strain.

3. The phase transformation features disappear gradually as the sample is compressed to higher level strains and is fully recoverable after the sample is annealed at $873 \mathrm{~K}\left(600^{\circ} \mathrm{C}\right)$ for $30 \mathrm{~min}$, even for samples with very large plastic deformation (e.g., 9.6\%); however, deformation above $\sim 7 \%$ strain leads to permanent plastic deformation which ultimately lowers the phase transformation temperatures.

\begin{abstract}
Acknowledgments This research was financially supported by startup funds of Dr. Xu Nie and Dr. Marcus L. Young. Dr. Xu Nie also thanks the Air Force Research Laboratory (AFRL/RW) for partial financial support under agreement number FA8651-14-2-0007. The authors would like to thank Scott Schlegel (ATI Specialty Alloys and Components, Albany, Oregon) and Brian Van Doren (Specialty Alloys and Components, Albany, Oregon) for useful discussions. NiTi SMA rods were supplied by ATI Specialty Alloys and Components, Albany, Oregon. The authors would like to acknowledge the Center for Advanced Research and Technology at University of North Texas for access to the experimental facilities used for this study.
\end{abstract}

\section{References}

1. Chau ETF, Friend CM, Allen DM, Hora J, Webster JR (2006) A technical and economic appraisal of shape memory alloys for aerospace applications. Mater Sci Eng A 438-440:589. doi:10. 1016/j.msea.2006.02.201

2. Hartl DJ, Lagoudas DC, Calkins FT, Mabe JH (2010) Use of a Ni60Ti shape memory alloy for active jet engine chevron application: I. Thermomechanical characterization. Smart Mater Struct 19:015020. doi:10.1088/0964-1726/19/1/015020
3. Benafan O, Brown J, Calkins FT et al (2013) Shape memory alloy actuator design: CASMART collaborative best practices and case studies. Int J Mech Mater Des 10:1. doi:10.1007/s10999-0139227-9

4. Petrini L, Migliavacca F (2011) Biomedical applications of shape memory alloys. J Metall 2011:1. doi:10.1155/2011/501483

5. Duerig T, Pelton A, Stöckel D (1999) An overview of nitinol medical applications. Mater Sci Eng A 273:149

6. Van Humbeeck J (1999) Non-medical applications of shape memory alloys. Mater Sci Eng A 273:134

7. Chen W, Bo S (2006) Temperature dependence of a NiTi shape memory alloy's superelastic behavior at a high strain rate. J Mech Mater Struct 1:339

8. Saadat S, Salichs J, Noori M et al (2002) An overview of vibration and seismic applications of NiTi shape memory alloy. Smart Mater Struct 11:218

9. McCormick J, DesRoches R, Fugazza D, Auricchio F (2006) Seismic vibration control using superelastic shape memory alloys. J Eng Mater Technol 128:294. doi:10.1115/1.2203109

10. Otsuka K, Wayman CM (1999) Shape memory materials. Cambridge University Press, Cambridge

11. Liu Y, Xie ZL, Van Humbeeck J, Delaey L (1999) Effect of texture orientation on the martensite deformation of NiTi shape memory alloy sheet. Acta Mater 47:645

12. Liu Y, Xie Z, Van Humbeeck J, Delaey L (1999) Some results on the detwinning process in NiTi shape memory alloys. Scr Mater 41:1273

13. Liu Y, Xie Z, Van Humbeeck J, Delaey L (1998) Asymmetry of stress-strain curves under tension and compression for NiTi shape memory alloys. Acta Mater 46:4325

14. Liu Y, Xie Z, Humbeeck JV, Delaey L, Liu Y (2000) On the deformation of the twinned domain in NiTi shape memory alloys. Philos Mag A 80:1935

15. Liu Y, Xie Z (2007) Detwinning in shape memory alloy. Progress in smart materials and structures. Nova Science Publishers Inc, New York, p 29

16. Liu Y, Liu Y, Van Humbeeck J (1998) Two-way shape memory effect developed by martensite deformation in NiTi. Acta Mater 47:199

17. Liu Y, Liu Y, Humbeeck J (1998) Lüders-like deformation associated with martensite reorientation in NiTi. Scr Mater 39:1047

18. Xie Z, Liu Y, Van Humbeeck J (1998) Microstructure of NiTi shape memory alloy due to tension-compression cyclic deformation. Acta Mater 46:1989

19. Ogawa K (1988) Characteristics of shape memory alloy at high strain rate. Le Journal de Physique Colloques 49:C3. doi:10.1051/ jphyscol:1988317

20. Chen WW, Wu Q, Kang JH, Winfree NA (2001) Compressive superelastic behavior of a NiTi shape memory alloy at strain rates of 0.001-750 s ${ }^{-1}$. Int J Solids Struct 38:8989

21. Nemat-Nasser S, Choi JY, Guo W-G, Isaacs JB, Taya M (2005) High strain-rate, small strain response of a NiTi shape-memory alloy. J Eng Mater Technol 127:83

22. Nemat-Nasser S, Choi J-Y, Guo W-G, Isaacs JB (2005) Very high strain-rate response of a NiTi shape-memory alloy. Mech Mater 37:287

23. Nemat-Nasser S, Guo W-G (2006) Superelastic and cyclic response of NiTi SMA at various strain rates and temperatures. Mech Mater 38:463. doi:10.1016/j.mechmat.2005.07.004

24. Miller DA, Thissell WR, Macdougall DAS (2000) Dynamic tensile plasticity and damage evolution in shape-memory $\mathrm{Ni}-\mathrm{Ti}$. Le Journal de Physique IV 10:Pr9. doi:10.1051/jp4:2000957

25. Jiang F, Vecchio KS (2007) Fracture of Nitinol under quasistatic and dynamic loading. Metall Mater Trans A 38:2907. doi:10. 1007/s11661-007-9349-5 
26. Millett JCF, Bourne NK, Gray GT (2002) Behavior of the shape memory alloy NiTi during one-dimensional shock loading. J Appl Phys 92:3107. doi:10.1063/1.1498877

27. Bragov A, Galieva A, Grigorieva V et al (2013) Functional properties of TiNi shape memory alloy after high strain rate loading. Mater Sci Forum 738-739:326. doi:10.4028/www.scien tific.net/MSF.738-739.326

28. Saletti D, Pattofatto S, Zhao H (2013) Measurement of phase transformation properties under moderate impact tensile loading in a NiTi alloy. Mech Mater 65:1. doi:10.1016/j.mechmat.2013. 05.017

29. Patman A, Swallowe GM (2009) A systematic investigation of the compressive behaviour of near equi-atomic NiTi over a range of strain rates and temperatures. In DYMAT-International Conference on the Mechanical and Physical Behaviour of Materials under Dynamic Loading, vol. 2, p. 1345. doi:10.1051/dymat/ 2009190

30. Adharapurapu RR, Jiang F, Vecchio KS, Gray GT (2006) Response of NiTi shape memory alloy at high strain rate: a systematic investigation of temperature effects on tension-compression asymmetry. Acta Mater 54:4609

31. Adharapurapu RR, Jiang F, Vecchio KS (2010) Aging effects on hardness and dynamic compressive behavior of Ti-55Ni (at.\%) alloy. Mater Sci Eng A 527:1665. doi:10.1016/j.msea.2009.10. 069

32. Adharapurapu RR, Jiang F, Bingert JF, Vecchio KS (2010) Influence of cold work and texture on the high-strain-rate response of Nitinol. Mater Sci Eng A 527:5255. doi:10.1016/j. msea.2010.04.076

33. Liu Y, Li Y, Ramesh K, Van Humbeeck J (1999) High strain rate deformation of martensitic NiTi shape memory alloy. Scr Mater 41:89

34. Qiu Y, Young ML, Nie X (2015) Influence of dynamic compression on phase transformation of martensitic NiTi shape memory alloys. Metall Mater Trans A. doi:10.1007/s11661-0153063-5
35. Mentz J, Frenzel J, Wagner MF-X et al (2008) Powder metallurgical processing of NiTi shape memory alloys with elevated transformation temperatures. Mater Sci Eng A 491:270

36. Rajagopalan S, Little AL, Bourke MAM, Vaidyanathan R (2005) Elastic modulus of shape-memory $\mathrm{NiTi}$ from in situ neutron diffraction during macroscopic loading, instrumented indentation, and extensometry. Appl Phys Lett 86:081901. doi:10.1063/1. 1863437

37. Young M, Wagner M-X, Frenzel J, Schmahl WW, Eggeler G (2010) Phase volume fractions and strain measurements in an ultrafine-grained NiTi shape-memory alloy during tensile loading. Acta Mater 58:2344

38. Liu Y, Xiang H (1998) Apparent modulus of elasticity of nearequiatomic NiTi. J Alloys Compd 270:154

39. Gall K, Tyber J, Brice V, Frick CP, Maier HJ, Morgan N (2005) Tensile deformation of NiTi wires. J Biomed Mater Res A 75:810. doi:10.1002/jbm.a.30464

40. Zadno G, Duerig T (1988) Linear and non-linear superelasticity in NiTi. Proc MRS Int Meet Adv Mater 9:201-206

41. Sakuma T, Mihara Y, Toyama H, Ochi Y, Yamauchi K (2006) Effect of cold working on transformation and deformation behavior after Pre-deforming in $\mathrm{Ti}-50$ at $\% \mathrm{Ni}$ shape memory alloy. Mater Trans 47:787

42. Eggeler G (2004) SMST 2003: Proceedings of the international conference on shape memory and superelastic technologies ASM International

43. Hornbogen E (2004) Review thermo-mechanical fatigue of shape memory alloys. J Mater Sci 39:385

44. Santamarta R, Seguı C, Pons J, Cesari E (1999) Martensite stabilisation in Ni 50 Ti 32.2 Hf 17.7. Scr Mater 41:867

45. Treppmann D, Hornbogen E (1997) On the influence of thermomechanical treatments on shape memory alloys. Le Journal de Physique IV 7:C5 